\title{
Toward Independent Nuclear Medicine, Molecular Imaging, and Theranostic Programs
}

\author{
Johannes Czernin \\ David Geffen School of Medicine at UCLA, Los Angeles, California
}

$T_{h}$ he Journal of Nuclear Medicine (JNM) has regained the leadership position among nuclear medicine and molecular imaging journals. JNM retained the \#5 position among more than 100 imaging journals. This success is owned by our authors, reviewers, readers, associate editors, editorial board members, and staff.

Associate editors voted for the best basic (1), translational (2), and clinical (3) manuscripts of the year. From these 3 categories, the associate editors elected the manuscript by Calais et al. (3) as best overall manuscript of the year. Two of the approaches described in these articles introduce (2) and apply (3) theranostic methods while one features a novel technique for imaging immune activation and immunotherapy (1). These selections are consistent with our mission as they represent the entire spectrum of academic achievements from bench to patients that move the field forward.

The introduction of new features such as "Discussions with Leaders" (4) or the "State of the Art" series (5) will continue to attract reader attention. We will continue to work hard, make improvements, publish even higher quality papers, stimulate discussions and debates, and enjoy controversies. We will push for a strong and well-integrated yet independent specialty of nuclear medicine with thriving departments in academia and community hospitals. The independence will arise from innovations in nuclear medicine, molecular imaging, molecular radiotherapy, and theranostics, resulting in academically and financially viable operations.

The JNM team hopes that you enjoy reading the journal as much as we enjoy creating the content.

\section{REFERENCES}

1. Donnelly DJ, Smith RA, Morin P, et al. Synthesis and biologic evaluation of a novel ${ }^{18} \mathrm{~F}$-labeled

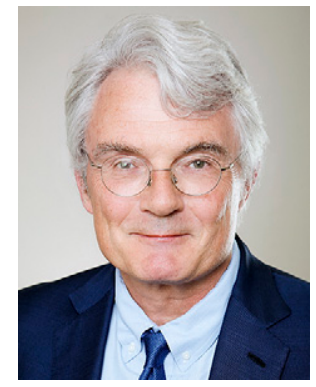

Johannes Czernin adnectin as a pet radioligand for imaging pd-11 expression. $J$ Nucl Med. 2018;59: 529-535.

2. Loktev A, Lindner T, Mier W, et al. A Tumor-imaging method targeting cancerassociated fibroblasts. J Nucl Med. 2018;59:1423-1429.

3. Calais J, Czernin J, Cao M, et al. ${ }^{68} \mathrm{Ga}$-PSMA-11 PET/CT mapping of prostate cancer biochemical recurrence after radical prostatectomy in 270 patients with a PSA level of less than $1.0 \mathrm{ng} / \mathrm{ml}$ : impact on salvage radiotherapy planning. $J$ Nucl Med. 2018;59:230-237.

4. Volkow N, Czernin J. A conversation between Nora Volkow and Johannes Czernin. J Nucl Med. 2019;60:717-720.

5. Cherry SR, Jones T, Karp JS, Qi J, Moses WW, Badawi RD. Total-body PET: maximizing sensitivity to create new opportunities for clinical research and patient care. J Nucl Med. 2018;59:3-12. 